\title{
REPRESENTACIONES SOCIALES Y ESTEREOTIPOS SOBRE VEJEZ Y PROCESOS DE ENVEJECIMIENTO EN EL CAMPO GERONTOLÓGICO DEL TRABAJO SOCIAL EN URUGUAY POR TERESA ISABEL DORNELL REGUEIRA
}

\section{SOCIAL REPRESENTATIONS AND STEREOTYPES ABOUT OLD AGE AND AGEING PROCESSES IN GERONTOLOGICAL SOCIAL WORK FIELD IN URUGUAY}

Fecha recepción: 23 de abril de 2018 / fecha aceptación: 21 de julio de 2019

Teresa Isabel Dornell Regueira ${ }^{1}$

Cómo citar este artículo:

Dornell, T (2019). Representaciones sociales y estereotipos sobre vejez y procesos de envejecimiento en el campo gerontológico del trabajo social en Uruguay. Revista Pensamiento y Acción Interdisciplinaria, 5(1), 108-126. DOI: http://doi.org/10.29035/pai.5.1.108

Resumen

La formación en vejez y envejecimiento ha sido y es un desafío en el campo académico del Trabajo Social, por ello, a más de una década del recorrido acumulativo del Área Vejez y Trabajo Social (AVYTS) y en función de implementación de estrategias diversas en el trabajo con estudiantes y profesionales de Trabajo Social y otras disciplinas de las ciencias sociales, es que se plantea una investigación que pretende sistematizar estos trayectos como caminos de acopio de saberes cargados de nociones y pre-nociones que orientan y penetran, transversalizando el accionar cotidiano de las prácticas pre-profesionales como profesionales.

Este proceso indagatorio pretende demostrar como los participantes reproducen pre-nociones en tanto imaginarios sociales sobre vejez y envejecimiento, que se constituyen en productos que las sociedades van construyendo a través de mecanismos de representaciones sociales que se trasmiten por la culturación, endoculturación y aculturación. Se parte del supuesto que a partir de los imaginarios construidos y comunicados se configurará un mapeo de caracterizar- caricaturizar la vejez desde las perspectivas del mundo tradicional y del mundo emergente e insurgente de ese ámbito de representaciones, como de sus formas procesuales de comprender la vejez y las vejeces.

El estudio presenta dos recorridas, por un lado, se estudiarán los discursos de los estudiantes del nivel avanzado que ingresaron a la licenciatura de Trabajo Social y optaron por el área de vejez (2009-2018) y por otro lado, se indagarán los discursos de profesionales de Trabajo Social y otras áreas de saber, como de estudiantes avanzados de la licenciatura de Trabajo Social

1 Uruguaya, Trabajadora Social, Licenciada en Trabajo Social, Diplomada en Investigación Social Cualitativa y Pedagogía Universitaria, Master en Gerontología Social, Docente Investigadora del Departamento de Trabajo Social de la Facultad de Ciencias Sociales de la Universidad de la República-Montevideo- Uruguay. Correo electrónico: teresa.dornell@cienciassociales.edu.uy 
(2010- 2018), que participaron en los Cursos de Educación Permanente de Vejez y Envejecimiento de la Facultad de Ciencias Sociales de la Universidad de la República. En este documento se trabajará en la segunda recorrida investigativa, con centralidad en la primer fase.

Palabras claves: Representaciones sociales- estereotipos- vejez- envejecimientoprofesionales universitarios

\begin{abstract}
Training in old age and aging has been and is a challenge in the academic field of Social Work, therefore, more than a decade of the cumulative journey of the Area Old Age and Social Work (AVYTS) and depending on the implementation of various strategies in the I work with students and professionals of Social Work and other disciplines of the social sciences, is that an investigation is proposed that aims to systematize these trajectories as ways of gathering knowledge loaded with notions and pre-notions that guide and penetrate, mainstreaming the daily actions of Pre-professional practices as professionals.

This investigative process aims to demonstrate how the participants reproduce pre-notions as social imaginary about old age and aging, which are constituted in products that societies are building through mechanisms of social representations that are transmitted through culture, endoculturation and acculturation. It is based on the assumption that, based on the imaginary constructed and communicated, a mapping will be configured to characterize and caricature old age from the perspectives of the traditional world and the emerging and insurgent world of that field of representations, as well as its procedural ways of understanding old age and old age.

The study presents two courses, on the one hand, the speeches of the advanced level students who entered the degree of Social Work and opted for the area of old age (2009-2018) will be studied and on the other hand, the speeches of Social Work professionals and other areas of knowledge, such as advanced students of the Bachelor of Social Work (2010-2018), who participated in the Courses of Permanent Education of Aging and Aging of the Faculty of Social Sciences of the University of the Republic . This document will work on the second research tour, with centrality in the first phase.
\end{abstract}

Keywords: social representations- stereotypes- old age- aging- university professionals.

\title{
Antecedentes generales
}

La formación en vejez y envejecimiento ha sido y es un desafío en el campo académico para el Trabajo Social, por ello, el análisis de la trayectoria del área vejez como ámbito universitario en la formación continua de estudiantes de grado de la Licenciatura de Trabajo Social del Departamento de Trabajo Social (DTS) en la Facultad de Ciencias Sociales (FCS) de la Universidad de la República (UdelaR), como en la actualización y profundización permanente de la temática en los profesionales del Trabajo Social, permite dar cuenta del desarrollo de la conformación del área, desde su génesis hasta la actualidad. 
Entre los años 2005- 2007 se comienza con las primeras prácticas pre profesionales con especificidad en vejez en el marco de las materias Metodología de la Intervención Profesional- nivel II y nivel III (MIP II- MIP III), correspondientes al Plan de Estudios 1992, de la Licenciatura en Trabajo Social, producto de la iniciativa de la encargada de la cátedra de MIP II y de algunos docentes dispersos en materias no específicas de la formación curricular, hito que permitió la concreción del Grupo de Estudios sobre Vejez (GEVEJ) en setiembre de 2008, que en el 2010 se convierte en el Área de Vejez y Trabajo Social (AVYTS).

Se podría afirmar, que un conjunto de componentes oficiaron de facilitadores, ya que hasta ese momento Trabajo Social a nivel académico presentaba una escasa discusión sobre la temática (1992 a 2003) pero, al comenzar el debate en torno al Nuevo Plan de Estudios (2009), que proponía formar núcleos temáticos en docencia/ extensión/ investigación, (2004/2005); junto a la incorporación de la temática en el Seminario Optativo de Salud y Sociedad (2005- 2011); permitió incrementar significativamente el número de estudiantes de grado en el marco de tutorías de tesis con estudios sobre Vejez y envejecimiento (2006 en adelante) y de manera expansiva el planteo de la importancia, vigencia y pertinencia del tema de Vejez.

En el escenario de esta discusión y junto a la inquietud e impulso de docentes y estudiantes avanzados de DTS-FCS-UdelaR, se expresa el interés de continuar profundizando en la temática, para generar debates y formalizar esta área de discusión para el colectivo de la profesión, pretendiendo aportar a la visibilidad y enunciabilidad de los procesos de subjetivación en la vejez. Así como, potenciar el desarrollo de una mirada académica que brindará soportes teóricos- conceptuales y metodológico-instrumentales, a los profesionales que desarrollan sus prácticas en esta área de hacer y del pensar de ese hacer.

La integración del primer grupo de trabajo contó con la participación de actores institucionales representantes del aparato estatal público y de actores universitarios que trabajarán sobre el tema. Este equipo de trabajo, después varias reuniones, trazo lineamientos generales a seguir centrados en:

(i) articulación permanente de los representantes de los espacios institucionales; (ii) pasantías interdisciplinares anuales de los estudiantes avanzados de la carrera en los ámbitos institucionales que conforman esta área; (iii) socialización- divulgación de los productos académicos elaborados en estos procesos de inserción, con la planificación e implementación de encuentros anuales y, (iv) creación o colonización de espacios de formación y actualización de la problemática central de estudio.

Hacia el año 2009, en función del debate e implementación de un nuevo Plan de Estudios los objetivos del equipo de trabajo se orientaron hacia: 
- Aportar en la discusión, sobre las representaciones socio- simbólicas de la Vejez, desde la perspectiva de la diversidad.

- Descifrar y deconstruir los sistemas y movimientos de objetivación subjetivación en el Adulto Mayor, para la comprensión del pensamiento fronterizo. (Dornell, 2009)

Desde su conformación, el grupo referente del Área, ha mantenido coordinaciones con diversas universidades de la región, principalmente con la Universidad Nacional de Entre Ríos y la Universidad de La Plata (Argentina); y a partir del año 2013 fue convocado oficialmente para integrar la Red Latinoamérica de Docentes Universitarios y Profesionales de Trabajo Social en el campo Gerontológico. (RedGETS).

Esta nueva estrategia de comunicación, habilitó el intercambio con profesionales de distintos países en torno a las perspectivas y prácticas dirigidas hacia la población vieja; además de contribuir a la apertura de diálogos fluidos e interpelantes que aporten al debate no solo de manera tangencial, sino desde una perspectiva que permita superar las fragmentaciones y el aislamiento regional e institucional. (Dornell, 2009)

Los principales ejes de análisis que desde el AVYTS, se propusieron en el período 2009-2014, fue a través de producciones del área, con la intencionalidad de dar cuenta de ese movimiento constante dentro y entre las diversas esferas que componen la cotidianeidad de los individuos (Dornell, 2009), cuyos nudos temáticos pretendieron dar cuenta de: (a) las formaciones históricas en torno a la Vejez, con contenidos del campo legible del saber: control moral y social; (b) estrategias hacia y con el Adulto Mayor, con contenidos de las relaciones con el mundo y sus fuerzas: mecanismos de poder y, (c) Los pliegues o procesos de subjetivación en la Vejez, con contenidos del pensamiento fronterizo: mecanismos de ruptura- franqueo de la línea institucionalizada.

El grupo elaboró ocho documentos de debate y difusión académica, entre docentes y egresados (2009 a 2010), aportando a la Unidad de Adulto Mayor en el Diploma de Intervención Familiar, como a la iniciativa en ofrecer la postulación y participación de Cursos de Educación Permanente en Vejez y Envejecimientos y sus complejidades en el abordaje de las profesiones de lo social y la salud avalados por FCS- de la R. A su vez, se convocó a Mesas de Diálogo a los Trabajadores Sociales, con intervención profesional específica en vejez (2009- 2011), lográndose compilar los materiales acumulados en los diversos eventos. (2010- 2012). 


\section{Problematización}

En esta línea, el recorrido del equipo permitió la acumulación de saberes y áreas de investigación que fue acompañar el movimiento propio de dicha complejidad; indagando y problematizando sobre los diversos cambios procesados en la transición de "adulto" a "viejo". Se partió de la necesidad de precisar y llegar a acuerdos en materia conceptual sobre la temática (noción de vejez, a la que se le acopla la de envejecimiento), considerando el impacto de los cambios en el entorno más inmediato (familia) y cómo era vivido por las propias personas, avanzando hacia la ruptura con el mundo del trabajo, y las estrategias pensadas hacia (políticas sociales) y con (redes sociales) el viejo. (Dornell, 2009)

Si bien, el abordaje de la Vejez y sus connotaciones han sido un área de ejercicio e intervención profesional histórica en Trabajo Social en Uruguay (inicios data de 1975), no se constituye como un campo de saber con una amplia sistematización de producciones, sino por el contrario, presenta un reducido acopio. Por eso, se reconoce la pertinencia de debatir e interpelar a la vejez, la cual forma parte de una construcción social cargada de significados, a partir de la que se toman decisiones, tanto a nivel del Estado, el Mercado y la Sociedad Civil. (Dornell; 2009)

Se entiende que los hallazgos que surjan de investigaciones e intervenciones en este campo de saber-hacer, podrán constituir instrumentos que permitirán potenciar las prácticas de los estudiantes, como de los profesionales de lo social y la salud que se encuentran implicados en estos procesos, así como, a los propios viejos. (Dornell; 2009)

El explorar y descubrir nuevos dispositivos para la comprensión de la vejez, parte de potenciar habilidades a lo largo de la vida de las personas, como son la inteligencia, la creatividad y la sabiduría, como herramientas que le permitan afrontar su propia existencia, en el sentido de seres envejecentes. La interpelación de vejez, no es sólo el abordaje de un hecho estadístico de descripción de fenómenos bio-psico-sociales, sino como la conclusión y prolongación de un proceso cultural como totalidad, que se inicia (Dornell, 2009) desde nuestros nacimientos.

A casi una década del recorrido acumulativo en AVYTS y en función de la implementación de estrategias diversas con estudiantes, profesionales y docentes de Trabajo Social, es que se plantea una investigación que se produce como consecuencia de pretender sistematizar estos trayectos, en tanto caminos de acopio de saberes cargados de nociones y pre-nociones que orientan y penetran y por ende transversalizan el accionar cotidiano de prácticas pre-profesionales, como profesionales.

El proceso indagatorio que se comienza a implementar se centra en poder dar cuenta de cómo los estudiantes y profesionales que participan en los distintos espacios gestionados por AVYTS, reproducen una serie de nociones en tanto 
imaginarios sociales sobre vejez y envejecimiento, que las propias sociedades van construyendo a través de mecanismos de representaciones sociales y que se trasmiten por los procesos de culturación, endoculturación y aculturación.

Estas representaciones pueden ser positivas o negativas sobre vejez y envejecimiento, si se concentran en imaginarios negativos, lleva a que las personas de esa sociedad generen formas de pensar y actuar discriminatorias y estereotipadas hacia ese grupo humano, donde la profesiones no escapamos a estos procesos de reproducción social no sólo con nuestros diálogos, sino con nuestras propias prácticas interventivas.

Desde que se ingresa a trabajar en el espacio de AVYTS, con los estudiantes como con los profesionales, se implementa una serie de dispositivos, a partir de la aplicación de una batería de instrumentos, con previo consentimiento de las personas implicadas en estos procesos de enseñanza, que habilita el poder debatir y problematizar estas representaciones sociales que forman y conforman el entramado social en referencia el tema de vejez y envejecimiento, en el entendido de que se hace imprescindible interpelar, comprender y complejizar nuestras prácticas profesionales, visibilizando, sensibilizando y contribuyendo a crear espacios de acción social, que permitan superar los estereotipos, mitos y prejuicios hacia las personas viejas. No se puede trabajar desde una dimensión ética de la autonomía si no se liberan las prácticas de las profesiones (como preprofesionales) de comportamientos y enunciados de heteronomía.

La presente investigación parte del supuesto que a partir de los imaginarios construidos y comunicados a través de los diversos dispositivos implementados, se configurará un mapeo de caracterizar- caricaturizar la vejez, presentando el fenotipo y genotipo de las/los viejas/viejos, junto a las pérdidas y ganancias en la vejez. Desde las perspectivas del mundo tradicional y del mundo emergente e insurgente de ese ámbito de representaciones y las formas procesuales de comprender la vejez y las vejeces.

El estudio presenta dos recorridas diferenciales, pero complementarias, por un lado, se estudiarán los discursos extraídos de los diversos dispositivos realizados con los estudiantes del nivel avanzado que ingresaron a la licenciatura de Trabajo Social y optaron por el área de vejez, en el período 2009 a 2018 y por otro lado, se indagarán los discursos expresados en el conjunto de instrumentos que se han implementado en los Cursos de Educación Permanente de Vejez y Envejecimiento a los estudiantes y profesionales de trabajo social y otras áreas, en período 2010 a 2018.

En el presente documento se trabajará sobre la segunda recorrida investigativa, centrados en la fase de ideación y no en la fase de concreción- complejización, con la finalidad de conocer las representaciones y estereotipos sobre vejez y envejecimiento que presentan los estudiantes avanzados de la carrera de trabajo 
social, los trabajadores sociales y otras profesiones de la salud y de lo social que han incursionado en cursos de actualización y profundización de saberes en este entramado del campo de la gerontología, que brinda el AVYTS- DTS- FCS- UdelaR.

\section{Marco Referencial}

Se abordarán dos encuadres centrales que oficiarán de marco referencial del estudio y permitirán reconfigurar la experiencia a la luz de los constructos teóricos: (1) Marco de contextualización de la experiencia, en tanto espacio de encuadre micro institucional y, (2) Marco conceptual, en tanto ámbito de encuadre teórico del momento de ideación.

\section{Marco de contextualización de la experiencia}

La información que se pretende sistematizar surge de la aplicación de una serie de dispositivos (entendiéndose éste como un medio que permite observar y registrar discursos en contextos determinados dispuestos a cumplir con su fin) que se implementaron en el proscenio del Curso de Educación Permanente, sobre Vejez y envejecimiento (2010-2018).

Los cursos se llevan a cabo una vez al año, generalmente en el segundo semestre y se requiere para su efectividad un cupo de 10 personas, donde los responsables de AVYTS acuerdan una cuota de no más de 20 personas. Se desarrolla por un período de dos meses en sesiones de una vez por semana de tres horas cada una, consta de exposiciones teóricas por parte del equipo docente organizador, junto a la participación de personas invitadas en una o dos instancias, como máximo, que son representantes de diversas disciplinas con trayectoria, en esta área de conocimiento.

El curso tiene una serie de requisitos como ser: asistencia obligatoria del 80 por ciento, de las sesiones planteadas en programa del Curso y el pago total de la matrícula antes de la última sesión de encuentro. A su vez, el equipo docente solicita la entrega de un trabajo final (de carácter no obligatorio, se brinda certificado y evaluación), de no más de 15 carillas (mínimo 10 carillas), siguiendo el formato explicitado por las normas APA (según año de actualización) y, se observa que en este período de casi una década que se desarrolla el curso, que en cada edición más de tres cuartas parte de los concurrentes presentan trabajo final para su evaluación.

Los contenidos comprendidos en las unidades temáticas, conforman un sistema articulado de conceptos que recorren las formas de nominar (nombrar) el devenir histórico y los hitos a destacar en el rol de los viejos, desde los filósofos griegos hasta la actualidad, con la contribución de miradas de diferentes culturas, 
pretendiendo que los participantes construyan una línea del tiempo sobre lo abordado conceptualmente.

Además, se profundizan los contenidos centrales de las dimensiones analíticas que nos brindan autores como Bourdieu, Goffman, Foucault y Giddens, entre otros, interpelarlos con los componentes sustantivos de vejez y envejecimiento, sin dejar de lado, las contribuciones de las teorías de Curso de vida (Elder), Teoría del Reconocimiento (Honneth) y Vida Cotidiana (Lefébvré y Heller).

La finalidad de los Cursos, era/es conformar espacios de reflexión y diálogo sobre lo alcanzado y por alcanzar en los ámbitos de inserción profesional y pre- profesional de las profesiones de la salud y lo social, siendo el interés principal recibir aportes en esta área de conocimiento desde la miradas de diversos autores del campo de las ciencias sociales y humanas, a través de compartir los núcleos centrales de debate en Vejez y Envejecimiento, habilitando un espacio de Intercambio entre los estudiantes, egresados y docentes, con el propósito de continuar con los avances sustantivos alcanzados en la temática y de la aportación de componentes sustanciales que impacten, no sólo el acervo investigativo, sino en la recorrida interventiva, que caracteriza y le da una impronta a las profesiones de la salud y lo social, con especial énfasis al campo de la gerontología social.

Para poder abordar la temática de los imaginarios sociales y conocer los imaginarios de los TS, estudiantes avanzados de TS y otras disciplinas del área de lo social y la salud, sobre la vejez y el envejecimiento, además de la batería de test que se implementan al comienzo del Curso, se realiza una evaluación individual al inicio como al final para observar la apropiación de los conocimientos brindados, sus propios conocimientos que se encontraban latentes y afloran, así como los cambios producidos sobre la mirada de la vejez, pasando en su mayoría de un punto de vista ingenuo y fenoménico hacia una mirada crítica.

\section{Marco conceptual que sustenta la discusión de la experiencia}

Antes de comenzar a exponer las interpelaciones teóricas-conceptuales que atraviesan y median las dimensiones en debate de vejez y envejecimiento, se debe explicitar que se concentraron en dos grandes sistemas categoriales. Los constructos de exploración de los imaginarios sociales: (a) circulo vicioso que contiene los estereotipos- prejuicios- prenociones sobre vejez y envejecimiento y (b) círculo virtuoso que comprenden las representaciones sociales de reconocimiento- autonomía- envejecimiento satisfactorio- placentero.

El dialogar sobre envejecimiento en las sociedades modernas capitalistas globalizadas -como son las del S. XXI-, implica tomar en cuenta factores económicos, políticos, sociales, culturales y tecnológicos. La población en Uruguay es altamente envejecida, representando el $20 \%$ del total del país, y sin embargo, muchas 
veces esta población es ignorada en cuanto a los aportes significativos que puede brindar a la estructura socio-económica y cultural.

Por eso, es imposible pensar en la vejez aislada del contexto sociocultural e histórico, la consideración de constructos que redefinen el concepto que llevaría a pensar que ha existido una vejez propia de cada tiempo y lugar, constituyendo nuevos imaginarios de la vejez.

No se debe olvidar, que es en las sociedades modernas, en donde el papel de las personas viejas sufre destacadas transformaciones, en especial cuando acaece la salida del mercado de trabajo, la que se constituye en un hito referenciado con la muerte en el proceso productivo, pasando a ser personas consideradas pasivas, no productivas, reafirmándose prenociones que conducen a estereotipos y discriminaciones.

La presencia de comportamientos de discriminación, estigmatización o estereotipo, implican un reconocimiento del otro diferente, pero la ruptura que más preocupa, es la construcción de sociedades indiferentes, que sobrepasan los rituales de discriminación y comienzan a edificarse en torno a la indiferencia, que supone colocar al otro al margen de su condición de persona, ese otro que no existe. Lo indiferente como comportamiento social, contiene aversión, provoca daño y dolor. Pero, el mantenerse al margen del otro, actúa como un mecanismo de protección de algo que no se quiere que ocurra, que hay que esconder, que es el temor a envejecer.

La imagen que la sociedad actual expresa sobre la vejez, refiere a representaciones negativas, predominando las prenociones que derivan en prejuicios; es así, que la noción de estigma, se relaciona con la idea de marcas o huellas que están presentes en lo físico de la persona, así como también en su alma, en su emocionalidad. El estigma no es otra cosa que una marca que está impreso en la persona y que marca su existencia. (Bembibre, 2010)

La palabra estigma se usa para designar a aquellas señales o huellas que marcan a una persona de diferentes formas, pueden relacionarse con personajes divinos o maléficos, y por lo general su presencia significa sufrimiento o dolor para aquellos que las portan, esta es la versión más concreta y práctica de la palabra estigma. (Bembibre, 2010)

En la actualidad, se mantiene un sentido similar al original, se designa al mal en sí mismo y no a sus manifestaciones corporales. Al encontrarnos frente a un extraño, las primeras apariencias permiten ver en qué categoría se encuentra y cuáles son sus atributos, siendo definiciones centrales en su identidad social. "Este extraño puede demostrar ser dueño de un atributo que lo vuelve diferente a los demás y lo convierte en alguien menos apetecible (malvado o débil). -A raíz de esto-, dejamos de verlo como una persona total y corriente, para reducirlo a un ser inficionado y menospreciado." (Goffman;2003,166) 
El estigma se convierte en una clase especial de atributo y estereotipo, que existe cuando se produce en los demás un descrédito amplio. La sociedad va categorizando a unos y otros, los coloca en una posición de desigualdad y desacreditación: a unos dentro de la categoría de normal y a otros dentro de la categoría de anormal, este proceso va construyendo estereotipos que marcan la relación con el otro desde la diferencia y que consiste en un desconocimiento del "otro".

Los estereotipos son ideas carentes de correspondencia empírica que suelen atribuir nociones falsas a determinados grupos. El estereotipo es un momento anterior a la estigmatización, el estigma implica un estereotipo, pero a su vez hace de ese estereotipo un objeto de discriminación.

Los prejuicios presentan dos componentes esenciales: (i) la actitud favorable o desfavorable y (ii) la vinculación a creencia excesivamente generalizada. Para Allport: "El hombre tiene una propensión al prejuicio. Ésta radica en su tendencia normal y natural a formar generalizaciones, conceptos, categorías, cuyo contenido representa una simplificación excesiva de su mundo de experiencias." (Allport; $1962,43)$

El prejuicio se comprende en la medida que se lo entienda como la hostilidad peculiar de la sociedad en la que aparece, el cual es situacional y se sitúa contra una categoría de personas, y se manifiesta en el trato con miembros individuales de grupos rechazados y forma la armonización de nuestra acción, de nuestra generalización categórica sobre un grupo dado, por eso se considera que alude a la predisposición favorable o desfavorable que acompaña a un juicio previo y sin fundamentos.

Esto no significa que el que es prejuicioso necesariamente discrimine, la discriminación siempre está basada en prejuicios y por lo tanto éste es el primer eslabón de posibles acciones discriminatorias. La diferencia fundamental entre prejuicio y discriminación se manifiesta en que mientras “... el prejuicio es una actitud, la discriminación es una acción: el prejuicio en acción”. (Allport; 1962, 29) Por ende, ambos conceptos están ligados.

Las personas en esta posición de no ser reconocidos, en el plano del no ser, desarrollan modalidades vinculares de desapego o frialdad, características que se presuponen son contrarias a la condición social que tienen los seres humanos, cuyo instinto gregario provoca que nos encontremos, relacionemos y cuidemos unos con otros de manera colectiva- junto a otros.

En estas circunstancias la sociedad aparece como adormecida (aletargada o amodorrada) y ejerce la elección de no sentir, construye esos sentimientos frente a determinados grupos humanos como son por ejemplo las personas viejas, desarrollando sentimientos de indiferencia, en el entendido de no reconocer, no ver aquello que no me preocupa, es decir no ver ni reconocer la vejez. 
El mostrar la indiferencia a alguien implica que se están retirando los sentimientos, colocando a las personas en un lugar de no existencia, pasando a ser portadores de otra imagen que no es aceptada- ni consensuada en roles socialmente preestablecidos, ni legitimados por el poder del orden vigente. Lugar en donde se ha ido construyendo y constituyendo en torno a la vejez, un imaginario social signado por el estigma, el prejuicio, el estereotipo y la discriminación, componentes que llevan a que se desafíe colectivamente estos constructos sociales y se de-construyan los mismos cuando se piensa en soluciones transformativas en el sentido de instituyentes al modelo vigente de viejismo- gerofóbico.

\section{Estrategia metodológica}

El proceso de investigación-sistematización, contará de dos momentos secuenciales: (i) el momento de ideación en él se presentará el qué, el por qué y el para qué del estudio y que conlleva a la fundamentación de los motivos y al encuadre teórico- conceptual de referencia, y (ii) el momento de concreción- complejización que corresponderá a la presentación de los datos obtenidos a través de la aplicación de una batería test. El momento de ideación presenta, la trayectoria histórica del encuadre de la experiencia y los constructos teóricos que la orientaron, que es el que se trabaja en este artículo.

El universo de estudio se orientó a tres grupos de participantes: Trabajadores Sociales, estudiantes avanzados de la Licenciatura de Trabajo Social de la FCSUdelaR y profesionales de disciplinas de la salud y las ciencias sociales y humanas.

El dominio empírico comprendió: (a) Los procesos discursivos de los participantes en cada edición de los Cursos de Educación Permanente sobre Vejez y envejecimiento, acerca de los estereotipos hacia las personas mayores y, (b) Las representaciones sociales de los participantes sobre el concepto de ser vieja/viejo.

Las fuentes en este proceso indagatorio supusieron la utilización de material documental obtenido de fuentes primarias, que se implementaron en la fase de ideación y que será sistematizado a través de los discursos extraídos de las respuestas obtenidas en la aplicación de una batería de test (2010-2018).

El material empírico fue obtenido a partir de cuatro test autoadministrados efectuados a cada una de las personas que concurrieron al curso sobre representaciones, nociones y prenociones de vejez y envejecimiento.

Las técnicas de recolección de datos fue una batería de cuatro test en donde las personas participantes registraron-textualmente sus opiniones. Esta batería de test se efectuó de manera secuencial en las primeras tres sesiones de las ocho, que contiene el curso, se inició con un formulario de relevamiento de datos de los 
inscriptos que aportan datos socio-demográficos y expectativas del curso, interrogante que se retoma al final del curso en la pauta de evaluación (último día de encuentro). Al final de la primera instancia, se aplicó el segundo test, en donde la persona solo tiene la opción de responder por lo afirmativo o por lo negativo sobre la vejez como proceso o como crisis.

En la segunda instancia, se aplicó una pauta con cuatro preguntas abiertas sobre cómo se vería en la vejez y que haría en esa etapa y al final de esta segunda instancia se aplicó el tercer dispositivo que era explicitar tres palabras claves que representarán a la vejez y fundamentarán esa elección. En la tercera instancia se implementó el cuarto dispositivo que es el Cuestionario de Estereotipos Negativos hacia la Vejez (CENVE).

En la fase de concreción-complejización se presentará los contenidos centrales de los cuatros instrumentos (test), y se procesará lo expresado por los participantes con su correspondiente tratamiento interpelativo, tema que no es el objeto de presentación en este trabajo.

\section{Resultados: Disputas preliminares}

Las multiplicidades de procesos interaccionales del sujeto con otros sujetos y con el objeto, se traducen en alteraciones, en tanto, variantes que van moldeando, en el entendido de formatear, los comportamientos de los sujetos. Estas prácticas individualizadoras y distintas del ser social, se constituyen en ese devenir en prácticas que afectan pareceres y opiniones, dándole una dinámica a la interacción social de superación de esas prácticas estacionarias o fragmentadas que no habilitan la aparición de prácticas sociales transformadoras.

El abordaje de la temática de Vejez se ha puesto en interpelación y ya no se habla de vejez sino de vejeces, en el sentido de nuevos pliegues como zonas de incertidumbre a navegar y conocer en esta etapa del curso de vida. Lo que se pretende expresar es que lo anteriormente discutido debe permitir iniciar un recorrido en tanto caminos en el contexto del descubrimiento que habilite el movimiento inacabado de hacerse y re-hacerse, de conocer y re-conocer, de posición sin imposición, que abra las puertas a maneras de pensar diversas, diferentes y distintas sobre temas o eventos similares.

El replanteo de las lógicas imperantes de los discursos instaurados hacia narrativas criticas (en el sentido de crisis del orden establecido), permiten a las profesiones que trabajan en el campo de la vejez y envejecimiento construir espacios conversacionales en donde los valores se van construyendo y de-construyendo, hasta lograr otras construcciones que generen nuevos cuadros axiológicos. 
El sujeto o los sujetos profesional/es, a través de las narrativas discursivas, conciben valoraciones en la comprensión de los objetos, que indagan en tanto verdades o pensamientos consensuados, que emiten juicios. Si estos elementos comunicantes presentan una connotación negativa en referencia a un constructo social, o sea, categoría analítica, aportarán a fundamentar las prácticas discriminatorias sustentadas por juicios-prejuiciosos, como ocurre en los constructos sociales que las sociedades modernas han construidos en torno a la vejez (mitos en la vejez) y el proceso de envejecimiento.

Un ejemplo, a destacar de lo anteriormente explicitado es la etapa del retiro laboral (prejubilación-jubilación) en donde las/las viejas/viejos al acercarse a la misma, comienzan a sentir emociones encontradas de pérdidas de lugares históricamente conquistados y reconocidos, para pasar a ocupar roles devaluados, con una carga negativa en los imaginarios sociales de producción económica o de aportes en lo cotidiano de la sociedad.

Las profesiones a igual que las personas viejas, no logran visualizar/sé cómo un sujeto activo y creador, con riquezas en la acumulación de experiencias y de proyecciones imaginativas, que permiten desbordar los límites en la producción de sentidos.

En el ámbito académico, los responsables en la formación del grado y postgrado deben/deberían brindar, conocimientos que aporten a esta superación de prejuicios, pre-nociones y estereotipos en la vejez y en el envejecimiento, como responsabilidad y como desafío ético de las profesiones, en especial de las que presentan una impronta interventiva, preguntándose interperlativamente sobre: ¿de qué se habla cuando se hace referencia al tema de los desafíos éticos de las profesiones con impronta interventiva en este proceso, no solo de producción de conocimientos, sino de acción social?, ¿Cuál/es son las protoformas de los imaginarios sociales, del campo de la Vejez con el Trabajo Social, desde sus ideas fundantes y problematizaciones?

Aparecen divergencias que conllevan a que se interpelen las desviaciones que se producen en los procesos de socialización primaria como secundaria. Si bien, la socialización primaria hace referencia a como los diferentes grupos de edades internalizan la realidad en el mundo de la vida cotidiana y así logran adquirir los conocimientos; en la socialización secundaria, las personas necesitan de los mantenimientos para esa realidad (articulación de los mantenimientos de rutinización y de los situacionales en las crisis).

El procedimiento que evitaría tensionar estos procesos de socialización primaria como secundaria, que irrumpen en los consensos comunicacionales, sería el acontecer del diálogo, como mediación que preservar la continuidad del mantenimiento de esa realidad compleja, contradictoria y en continuo cambio. 
Este proceso mixto de pretender desvincular lo vinculante, pero a su vez de desunir lo adosado de las narraciones, con la intencionalidad de entrar consintiendo y salir emergiendo de esos plexos, logra posicionar a las profesiones en desafíos crítico-reflexivo, no solo de las experiencias acumuladas de las/los viejas/ viejos, sino de las deliberaciones internalizadas que ellas/ellos enuncian en ese compartir. (Dornell, 2019)

\section{Conclusiones}

\section{Aproximación al proceso de consumación}

Un camino que introduzca a la reflexión y superación de estas discriminaciones, implica pensar formas de convivencia y encuentros sociales de respeto, conocimiento y reconocimiento hacia los viejos, con acuerdos en los cuales coexistan cambios en la estructura cultural- valorativa subyacente, que eleve la autoestima de los grupos irrespetados y modifique la imagen que los miembros tienen de sí mismos y de los demás; con un nuevo sentido de respeto.

Por eso, la importancia de aportar una mirada académica que brinde un soporte teórico y metodológico- instrumental a los profesionales que desarrollan sus prácticas en esta área (Dornell; 2009) de saber (producción de conocimientos) y de hacer (intervención de las profesiones), ambicionando que la complejidad de la construcción de la persona humana, así como, de las distintas generaciones por las que se va atravesando en el proceso de su vida, impliquen no descuidar la comprensión de la vida cotidiana de cada individuo, el contexto donde se desarrolla y cada historia personal (analizándose lo propio en cómo incide en ese envejecimiento).

En la modernidad, los conocimientos son provocados por un sujeto creador, un sujeto o un conjunto de sujetos (personas), que los adquieren por la apropiación de los componentes centrales que nos brinda ese objeto que va a ser estudiado- investigado-indagado. Aquí, el sujeto cognoscente, es aquel que realizará una serie de acciones articuladas, condicionadas por el contexto socio- político y cultural que le desplegará direccionalidad a la actividad práctica. El contexto oficiara de ordenador de los conocimientos, en tantos textos caóticos que interpelan la realidad.

Mientras, que en la postmodernidad los conocimientos surgen de acciones que los sujetos realizan a partir de prácticas procesuales que se construyen y reconstruyen en esa realidad de permanente cambio y trasformación. Los textos en estos contextos de cambios, producirán estructuras de pensamiento a partir de las intersubjetividades de los sujetos. 
Es así, que se hace alusión a la destrucción de las narrativas dominantes, donde el sujeto comienza a incursionar en un mundo cuyo sentido comienza a ser sin sentido y la primacía de las representaciones empiezan a ser interrogantes de lo cotidiano que se fragmentan. Es aquí, donde las profesionales de lo social deben ser capaces de posibilitar la construcción de un actor social diferente en su estado de vejez, replanteando y re-significando el lugar de los viejos/as en la sociedad actual, promoviendo su involucramiento contestatario e insurgente.

Partir del dialogo continuo y permanente como sujetos cognoscentes (determinados por la cultura y las relaciones sociales particulares de la época) con las viejas y los viejos de nuestras sociedades, es que se originan nuestros compromisos y responsabilidades éticas, sociales y políticas como profesionales. La apropiación de la realidad en su complejidad es un proceso de aprendizaje, que, para conocerla y transformarla, nos coloca en actores cognoscentes propositivos, dialógicos y críticos que desmitifican las representaciones dominantes del conocimiento.

El aprender implica comprensión, implica procesos de cognición y construcción de significados, en base a la interacción reciproca y significativa de los aportes construidos. Los campos de conocimiento de las disciplinas fueron construyendo y construyen debates en torno al pasaje de los enfoques medicalizadores en la mirada del sujeto a conocer, (que aún perduran en los saberes y prácticas de las profesiones) hacia una mirada de la producción socio- histórica de la subjetividad de los sujetos y con esto la aparición de movimientos de expresión en el reconocimiento de las vejeces y envejecimiento y sus potenciales transformaciones.

Las interpelaciones discursivas en la producción de conocimiento en las profesiones, deberían reedificar la producción socio- histórica de la subjetividad, como espacio instituyente de construcción de relaciones dialógicas en la vida humana. (Dornell 2019)

Esas interacciones de dialogo se desarrollan en un escenario contextual que es la vida social, en el sentido de espacio de la realidad socio-cultural del diario vivir, del aquí y ahora, el cual para comprenderlo no se debe olvidar que esta signado por el ayer que lo creo y el futuro que lo reproducirá o cambiará.

Por ello, la responsabilidad del mundo académico, como formador del recurso humano de las profesiones y como estudiosos de las sociedades, debería tener en su agenda el compromiso de la defensa de los derechos humanos de las personas en clave de derechos y equidad, así como la promoción de espacios de participación de manera conjunta con los diversos colectivos de la sociedad civil.

El desafío para las personas mayores debería ir en sentido, por un lado, el conocer y asumir los cambios a nivel biológico, psicológico, cultural, económico y social y por otro lado, el lograr que la sociedad cambie la postura de rechazo a las personas por alguna característica en particular, en el entendido de actitud marginadora del que envejece. 
Las sociedades deben pensar en estrategias elaboradas desde, con y para las personas mayores, a través de una construcción que esté libre de estigmas a través de la cual, el viejo se perciba como viejo y no como enfermo, y que contribuya a transitar objetiva y subjetivamente por un proceso de envejecimiento placentero-satisfactorio.

La protección de los derechos para las personas viejas, debe pasar por la superación de estereotipos negativos a partir de fomentar y respaldar el fortalecimiento de imaginarios y representaciones sociales positivas en las sociedades con un acompañamiento continuo de un trabajo sostenido en el tiempo con esfuerzo de múltiples actores involucrados.

Lo que se pone en debate es la manera en como las disciplinas/profesiones fueron produciendo y adquiriendo esos conocimientos que se presentaban como coherentes y correctos para responder el accionar cotidiano de los retos en el diario vivir, frente al cómo se irán introyectándo los nuevos que se están construyendo y sobrevendrán a los añejos en esa cotidianeidad.

La aparición de estas contradicciones en los conocimientos adquiridos y aceptados socialmente frente a los nuevos que se comienzan a aprender, deberían generar prácticas distintivas de reconocimiento y autonomía, que habiliten a pensar a este campo de conocimientos y experiencias como campo de turbulencias, de problemas a complejizar, de temas a interpelar desde lógicas colectivas emancipadoras, que intentan des-disciplinar y des-naturalizar. (Dornell, 2019)

Se considera que brindarle continuidad a este proceso indagatorio en su segunda fase de concreción-complejización, oficiará de insumo para demostrar que en el espacio de postgraduación, los profesionales a través de la educación continua, logran interpelar estereotipos prenocionales en ese intercambio continuo del devenir formativo que le habilita a problematizar de-construyendo posicionamientos rígidos y unilaterales de la razón analítica, hacia posicionamientos críticos desde la razón dialéctica, superando miradas atemporales, acríticas y ahistóricas de la vejez.

El movimiento de indagación para comprender, desentrañar, y dilucidar lo que empieza a emerger en la vejez y el envejecimiento, prepara a las profesiones en una incursión de caminos o recorridas trayectoriales donde el descifrar y desembrollar, se constituyen en hitos interpelantes de las pluralidades complejas. (Dornell; 2019) 


\section{Referencias}

Allport, G (1962). La naturaleza del prejuicio. Temas de EUDEBA. Buenos Aires: Editorial Universitaria.

Dornell, (Coord.) (2019). Vejez, vulnerabilidad y derechos humanos III Congreso Latinoamericano de Teoría Social. Desafíos contemporáneos de la Teoría Social. Buenos Aires: Universidad de Buenos Aires.

Dornell, T., Mauro, R., Stemphelet, S. \& Sande, S. (2015). El desafío del cuidado humano en Uruguay: Dilemas para el Trabajo Social. En Paola, J., Tordo, M. \& Danel, P. Más mayores, más derechos: diálogos interdisciplinarios sobre vejez. La Plata: EDULP.

Dornell, T., Sande, S. \& Aguirre, M., (2014). La Valoración Social en el envejecimiento y la vejez (2011). En Lera, C. (Comp), Debates y proposiciones de Trabajo Social en el marco del Bicentenario (pp. 161-171). Paraná: Universidad Nacional de Entre Ríos. Recuperado de http://www.fts.uner.edu.ar/publicaciones/ publicaciones/libros/Debates_p_TS_m_Bicentenario.pdf.

Dornell, T. (2011). Complejidades en el abordaje de la Vejez y el envejecimiento.

(2011). Debate sobre bienestar en la vejez. Carta Geriátrica Gerontológica 4.

(2009). Lo visible y lo enunciable en la vejez. Área de Vejez y Trabajo Social. DTS-FCS-Universidad de la República. Documentos de Trabajo. En Mauros, R. El desafío del cuidado humano en Uruguay: Dilemas para el Trabajo Social. Área de Vejez y Trabajo Social. DTS-FCS-Universidad de la República, Documentos de Trabajo. Trabajo presentado en las XIII Jornadas de Investigación de la Facultad de Ciencias Sociales, Universidad de la República, Montevideo, 15-17 de septiembre de 2014.

(2009). ¿Qué significado tiene para los/as viejos/as el mundo del trabajo? Área de Vejez y Trabajo Social. DTS-FCS- Universidad de La República. Documentos de Trabajo.

(2009). Conceptualizando la vejez en el Uruguay. Área de Vejez y Trabajo Social. DTS-FCS-Universidad de la República; Documentos de Trabajo. En Mauros, R. El desafío del cuidado humano en Uruguay: Dilemas para el Trabajo Social. Área de Vejez y Trabajo Social. DTS-FCS-Universidad de la República, Documentos de Trabajo. Trabajo presentado en las XIII Jornadas de Investigación de la Facultad de Ciencias Sociales, Universidad de la República, Montevideo, 15-17 de setpiembre de 2014. 
(2009). Las transformaciones familiares y sus repercusiones en la vejez. Área de Vejez y Trabajo Social. DTS-FCS. Universidad de la República; Documentos de Trabajo.

Goffman, E (2003). Estigma. La identidad deteriorada. Buenos Aires: Amorrortu. Vattimo, G (1991). La ética de la interpretación. España: Paidos. 
Representaciones sociales y estereotipos sobre vejez y procesos de envejecimiento en el campo gerontológico del trabajo social en Uruguay por Teresa Isabel Dornell Regueira

Dirección de correspondencia:

Teresa Isabel Dornell Regueira. Trabajadora social, Master en Gerontología Social. Académica Universidad de la República-Montevideo- Uruguay

Contacto:

teresa.dornell@cienciassociales.edu.uy 